\title{
RESISTIVITY AND TEMPERATURE COEFFICIENT OF RESISTIVITY OF THE Fe/Zr MULTILAYER FILMS
}

\author{
T. LUCIŃSKI AND F. STOBIECKI \\ Institute of Molecular Physics, Polish Academy of Sciences \\ Smoluchowskiego 17/19, 60-179 Poznań, Poland
}

\begin{abstract}
The resistivity $(\rho)$ and temperature coefficient of resistivity (TCR) dependencies on modulation wavelength $(\lambda)$ were examined in $\mathrm{Fe} / \mathrm{Zr}$ multilayer thin films. It was shown that the $\rho(\lambda)$ and $\operatorname{TCR}(\lambda)$ behaviours can be explained on the basis of the assumption that the amorphous phase can be spontaneously formed during the deposition process. We found that the effective thickness of the amorphous phase was $\approx 2 \mathrm{~nm}$ per single interface. PACS numbers: 75.50.-y
\end{abstract}

\section{Introduction}

Amorphization of crystalline multilayer structures caused by solid state reaction has been established for many metallic systems including $\mathrm{Fe} / \mathrm{Zr}$ artificial structures $[1,2]$.

Kiauka and coworkers [3] using the conversion electron Mössbauer spectroscopy showed that an amorphous Fe-Zr phase could be formed during a deposition process. They found that a layer of interfacial $\alpha$-Fe of thickness of $\approx 2 n$ at most was transformed into an amorphous phase.

Kopcewicz [4] and Kraegermann [5] showed that for $n(\mathrm{Fe})=n(\mathrm{Zr})<10$ monolayers of both sputtered and electron beam-deposited $\mathrm{Fe} / \mathrm{Zr}$ multilayers were entirely amorphous.

The formation of the amorphous phase in multilayered $\mathrm{Fe} / \mathrm{Zr}$ thin films was also investigated by resistivity measurements [6] which gave the information about the spatial distribution of crystalline and amorphous phases by comparison with a network of parallel and series resistances.

According to Kiauka [3] at least two amorphous magnetically oriented phases exist in the as-deposited $\mathrm{Fe} / \mathrm{Zr}$ multilayers probably due to a $\mathrm{Fe}$ concentration gradient across the amorphous layer.

In the present paper the appearance of an amorphous phase in the as-deposited $\mathrm{Fe} / \mathrm{Zr}$ multilayered films is shown on the basis of the electrical resistivity studies. Applying different resistivity models for the layered films we intend to show how the amorphous phase can be distributed in a polycrystalline $\mathrm{Fe} / \mathrm{Zr}$ layered matrix. 


\section{Experimental}

Polycrystalline $\mathrm{Fe} / \mathrm{Zr}$ multilayered films were prepared by double face-to-face cosputtering.

The total thickness of the samples was $d \approx 230 \mathrm{~nm}$ and the modulation wavelength was $1.2 \mathrm{~nm}<\lambda<12 \mathrm{~nm}\left(\lambda=d_{\mathrm{Fe}}+d_{\mathrm{Zr}}\right.$, where $d_{\mathrm{Fe}}$ and $d_{\mathrm{Zr}}$ are $\mathrm{Fe}$ and Zr sublayer thicknesses, respectively). The number of bilayer was $20 \leq N \leq 200$. The sublayer thickness ratio $d_{\mathrm{Fe}} / d_{\mathrm{zr}}$ was $2: 1$. The wavelength of modulation $\lambda$ and sublayer thicknesses were determined by small angle X-ray diffraction and $\mathrm{X}$-ray fluorescence analysis. The error in the thickness determination was smaller than $5 \%$.

The electrical resistivity $(\rho)$ and temperature coefficient of resistivity (TCR) were measured on the as-deposited samples at room temperature and as a function of temperature $(290 \mathrm{~K}<T<750 \mathrm{~K})$.

\section{Results and discussion}

Figure 1 provides examples of the temperature dependencies of resistivity for two $\mathrm{Fe} / \mathrm{Zr}$ multilayers with $\lambda=1.96 \mathrm{~nm}$ and $\lambda=5.9 \mathrm{~nm}$. It is clearly seen

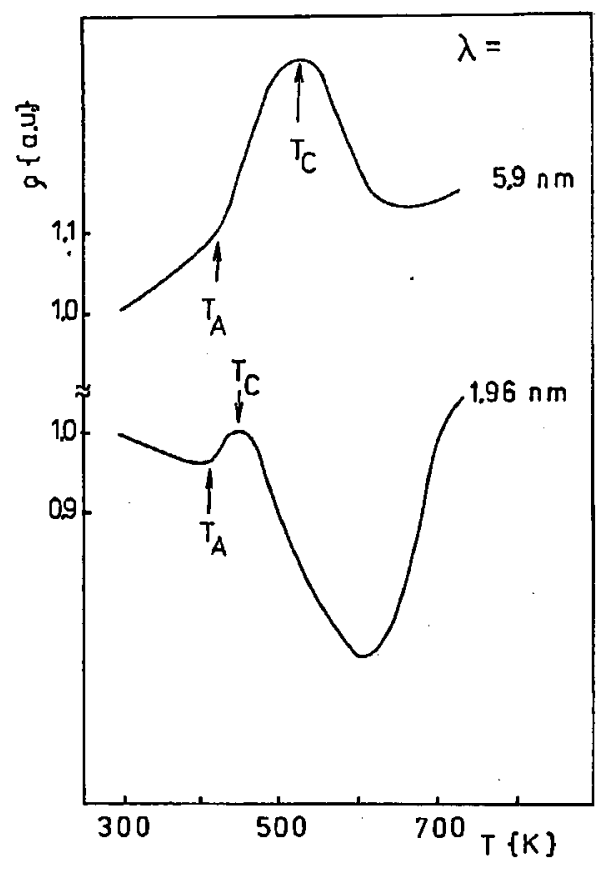

Fig. 1. The examples of the temperature dependencies of the resistivity for two $\mathrm{Fe} / \mathrm{Zr}$ multilayers with $\lambda=1.96 \mathrm{~nm}$ and $\lambda=5.9 \mathrm{~nm} . T_{\mathrm{A}}$ and $T_{\mathrm{C}}$ indicate the beginning of formation of the amorphous and crystalline phases, respectively. 
that the $\rho(T)$ behaviour is different at high and low values of $\lambda$. The amorphous phase formation (solid-state reaction) is visualized by increase in the resistivity which starts at about $420 \mathrm{~K}\left(T_{\mathrm{A}}\right)$ for both samples. The progressive growth of the amorphous phase can be observed.

Crystallization process of the previously formed amorphous phase can be observed at higher temperatures $\left(T_{\mathrm{C}}\right)$ and is accompanied by the decrease in the resistivity.

Figure 2 presents the collected resistivity and TCR data as a function of $\lambda$ for the as-deposited $\mathrm{Fe} / \mathrm{Zr}$ multilayers with $d_{\mathrm{Fe}} / d_{\mathrm{Zr}}=2: 1$.

The resistivity decreases with increasing $\lambda$; simultaneously an increase in TCR occurs. The TCR in the vicinity of $\lambda=2 \mathrm{~nm}$ takes negative values.

The only phase in $\mathrm{Fe} / \mathrm{Zr}$ multilayer system exhibiting a negative TCR is the amorphous one. Hence, the change in sign of TCR gives conclusive evidence that an amorphous phase is formed during the deposition process. We suppose that decreasing TCR suggests also that an amorphous phase can be formed in the $\mathrm{Fe} / \mathrm{Zr}$ multilayers in the whole range of $\lambda$, but for $\lambda$ very close to $2 \mathrm{~nm}$ the multilayers are likely to be almost completely amorphous.

In order to check our suppositions about the existence of the amorphous phase in the as-deposited samples the resistivity of the $\mathrm{Fe}, \mathrm{Zr}$, and amorphous $\mathrm{Fe}-\mathrm{Zr}$ thin films has been measured. We obtained the values $0.412 \mu \Omega \mathrm{m}, 1.00 \mu \Omega \mathrm{m}$ and $2.07 \mu \Omega \mathrm{m}$ for the films given above, respectively.

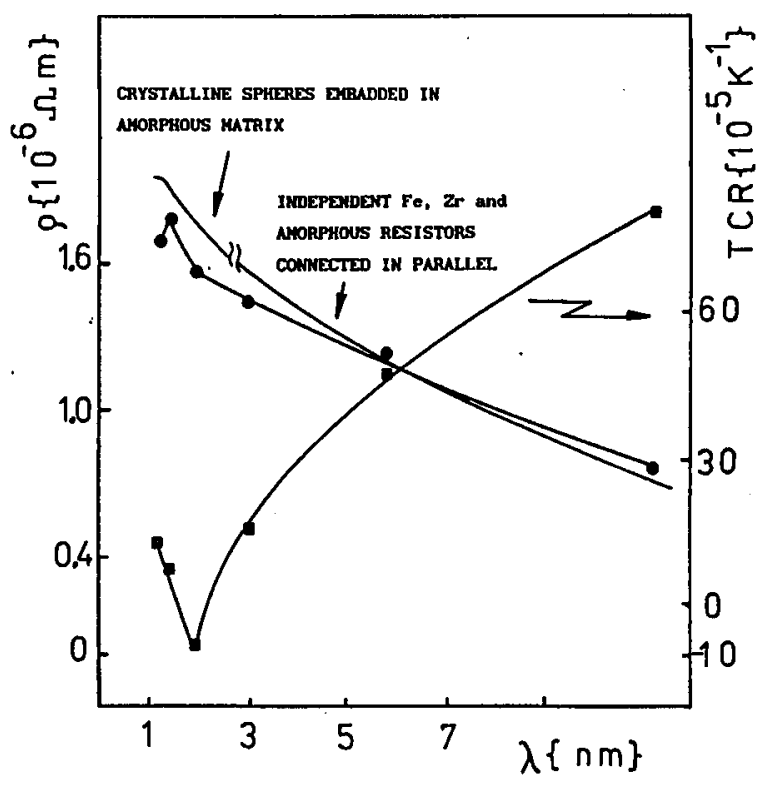

Fig. 2. The collected resistivity and TCR experimental data as a function of $\lambda$ for the as-deposited $\mathrm{Fe} / \mathrm{Zr}$ samples. Experimental data were taken at room temperature. The calculated from Eqs. (1) and (2) $\rho(\lambda)$ values are represented by the solid line with no points. 
Two resistivity models were taken into account in order to explain the $\rho(\lambda)$ behaviour.

In the first one we assumed that the $\mathrm{Fe} / \mathrm{Zr}$ multilayers could be treated as independent resistors connected in parallel. In this case we assumed that the spontaneous formation of an amorphous phase (or amorphous phases) during the deposition process occurred at the interface between $\mathrm{Fe}$ and $\mathrm{Zr}$ sublayers (planar growth of an amorphous phase). Then the resistivity of the sample can be written as

$$
\rho=d\left(\rho_{\mathrm{Fe}} \rho_{\mathrm{Zr}} \rho_{\mathrm{a}}\right)\left(d_{\mathrm{Fe}} \rho_{\mathrm{Zr}} \rho_{\mathrm{a}}+d_{\mathrm{Zr}} \rho_{\mathrm{Fe}} \rho_{\mathrm{a}}+d_{\mathrm{a}} \rho_{\mathrm{Fe}} \rho_{\mathrm{Zr}}\right)^{-1},
$$

where $d$ denotes the total film thickness, $\rho_{\mathrm{a}}$ is the resistivity of the amorphous phase and $d_{\mathrm{Fe}}$ and $d_{\mathrm{Zr}}$ are the effective thicknesses of $\mathrm{Fe}$ and $\mathrm{Zr}$ sublayers, respectively. $d_{\mathrm{a}}$ is the thickness of the already existing amorphous phase. The thicknesses $d_{\mathrm{Fe}}$, $d_{\mathrm{Zr}}$ and $d_{\mathrm{a}}$ were treated as the fitting parameters.

We found the best fitting quality when the amorphous phase was formed by $1.5 \mathrm{~nm}$ of $\mathrm{Fe}$ and $0.75 \mathrm{~nm}$ of $\mathrm{Zr}$ at the single interface. It means that the average composition of the amorphous phase was $4 \mathrm{Fe}$ atoms per $1 \mathrm{Zr}$ atom. Hence, the simple model of the resistors connected in parallel can be applied only for $\lambda>2.2 \mathrm{~nm}$.

The second resistivity model for $\lambda<2.2 \mathrm{~nm}$ and the analysis of the resistivity results is based on Maxwell's [7] treatment of a system composed of a number of randomly distributed crystalline spheres of the same resistivity embedded in an amorphous matrix of a different resistivity. In this case we can write

$$
\rho=\rho_{\mathrm{a}}\left[\rho_{\mathrm{c}}\left(2 d-d_{\mathrm{c}}\right)+\rho_{\mathrm{a}}\left(d-d_{\mathrm{c}}\right)\right]\left[2 \rho_{\mathrm{c}}\left(d-d_{\mathrm{c}}\right)+\rho_{\mathrm{a}}\left(d+2 d_{\mathrm{c}}\right)\right]^{-1},
$$

where $\rho_{c}$ denotes the resistivity of the crystalline spheres and $d / d_{c}$ is the volume fraction of the $\mathrm{Fe}$ or $\mathrm{Zr}$ crystallites in the amorphous matrix.

In our calculation we made the same assumption as before, namely that an amorphous phase can be formed by $4 \mathrm{Fe}$ atoms and $1 \mathrm{Zr}$ atom. We took as $\rho_{\mathrm{c}}$ the $\rho_{\mathrm{Fe}}$ or $\rho_{\mathrm{Zr}}$ values depending on which crystalline metal stayed partially chemically unreacted.

Our calculated results are shown in Fig. 2. It can be seen that the $\rho(\lambda)$ behaviour can be well explained by the use of two resistivity models described above with the assumption that an effective thickness of the amorphous phase to be formed at the interface is about $2 \mathrm{~nm}$.

\section{Conclusion}

The resistivity and temperature coefficient of the resistivity dependencies on $\lambda$ were examined in $\mathrm{Fe} / \mathrm{Zr}$ multilayer films.

The $\rho(\lambda)$ and TCR $(\lambda)$ behaviours were explained on the basis of the assumption that the amorphous phase already exists in the as-deposited samples.

Two resistivity models have been succesfully applied in order to explain the $\rho(\lambda)$ behaviour. The first one described the $\mathrm{Fe} / \mathrm{Zr}$ multilayers with $\lambda>2.2 \mathrm{~nm}$ as the independent resistors connected in parallel, and the other one described the $\mathrm{Fe} / \mathrm{Zr}$ multilayers with $\lambda<2.2 \mathrm{~nm}$ as the system composed of the number of 
the randomly distributed crystalline $\mathrm{Fe}$ or $\mathrm{Zr}$ spheres embedded in the amorphous matrix.

We found that the spontaneous formation of the amorphous phase occurred, corresponding to the effective thickness $d_{\mathrm{a}} \approx 2 \mathrm{~nm}$ per single interface.

\section{Acknowledgment}

This work was financially supported by project No. 223119102 of the Committee for Scientific Research.

\section{References}

[1] B.M. Clemens, M.J. Suchoski, Appl. Phys. Lett. 47, 943 (1985).

[2] H.U. Krebs, D.J. Webb, A.F. Marshall, Phys. Rev. B 35, 5392 (1987).

[3] W. Kiauka, W. Keune, T. Shinjo, N. Hosoito, J. Magn. Magn. Mater. 93, 494 (1991).

[4] M. Kopcewicz, D.L. Wiliamson, Hyperfine Interact., in press.

[5] S. Kraegermann, F. Stobiecki, T. Stobiecki, K. Roell, J. Magn. Magn. Mater. 101, 209 (1991).

[6] T. Otto, T. Stobiecki, F. Stobiecki, K. Roell, J. Magn. Magn. Mater. 101, 207 (1991).

[7] J.C. Maxwell, A Treatise on Electricity and Magnetism, Vol. 1, Dover, New York 1954, p. 440. 